International Journal of Physical Sciences and Engineering
Available online at http://sciencescholar.us/journal/index.php/ijpse
Vol. 2 No. 3, December 2019, pages: $1 \sim 6$
e-ISSN : 2550-6943, p-ISSN : 2550-6951
https://doi.org/10.29332/ijpse.v3n3.351

\title{
The Linearity of X-ray Devices Radiation Output and Its Relationship with Patient Thickness
}

\author{
I Gusti Agung Ayu Ratnawati a, Ni Komang Tri Suandayani b , Gusti Ngurah Sutapa c
}

Article history: Received 09 April 2019 , Accepted: 30 August 2019, Published: 02 November 2019

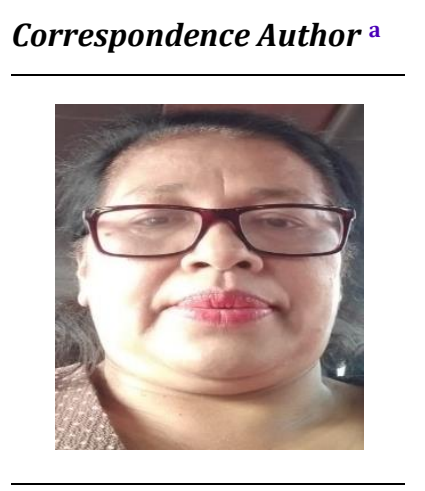

Keywords

devices radiation; output linearity, patient thickness; quality control-QC, X-ray;

\begin{abstract}
The utilization of X-rays in the medical field is one way to improve public health. X-rays are one of the applications of radiation for radio diagnostics. Xray examination using X-rays can provide information about the human body without the need for surgery. In the use of radiation technology it is realized that in addition to its use for radio diagnostics, X-rays harm the environment and living things around them, especially radiation workers. The impact that can result in cancer due to the accumulation of radiation dose exposure received by the body exceeds the specified threshold dose. Therefore safety standard guidelines that contain basic requirements for quality control (Quality Control -QC) must be obeyed. One of the test activities included in the QC program is the linearity test of X-ray radiation output. This radiation output linearity is a level of radiation output that is proportional to the use of various exposures $(\mathrm{kV}$ and $\mathrm{mA})$. Radiation output linearity is the ability of a radiographic aircraft to produce a constant radiation output from various combinations of $\mathrm{kV}, \mathrm{mA}$, and $\mathrm{X}$-ray exposure time. The purpose of this study is to determine the linearity of radiation exposure that must be in the tolerance of $\leq 10 \%$ of each pair of exposure time with a predetermined exposure. The results of radiation output measurements (mGy) against several exposure values (mAs) show the linear linearity of radiation output. The linearity of Xray radiation output is still at a tolerance below $10 \%$. The patient's body thickness significantly $(\mathrm{P} \leq 0.05)$ received a larger dose.
\end{abstract}

e-ISSN: 2550-6943, p-ISSN: 2550-6951 ๑Copyright 2019. The Author. SS Journals Published by Universidad Técnica de Manabí. This is an open-access article under the CC BY-SA 4.0 license (https://creativecommons.org/licenses/by-sa/4.0/) All rights reserved.

\section{Contents}

Abstract

1. Introduction.

a Udayana University, Denpasar, Indonesia

b Udayana University, Denpasar, Indonesia

c Udayana University, Denpasar, Indonesia 


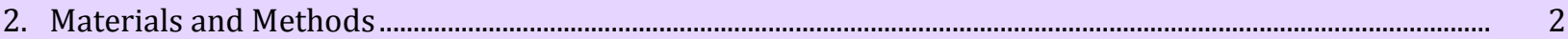

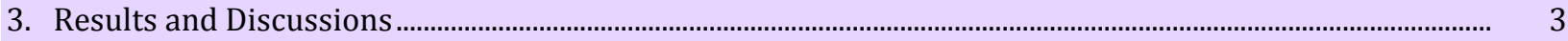

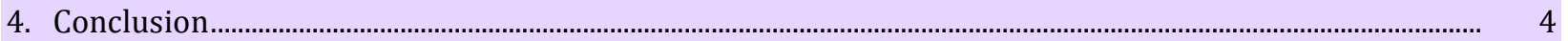

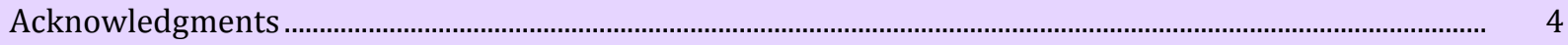

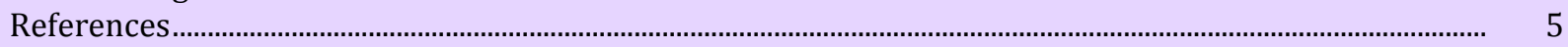

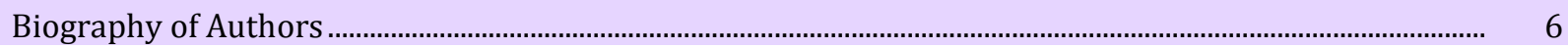

\section{Introduction}

The use of X-rays in the medical field is one way to improve public health. X-rays are one of the applications of radiation for radio diagnostics. X-ray examination using X-rays can provide information about the human body without the need for surgery (Chamber, 1983). In the use of radiation technology it is realized that in addition to its use for radio diagnostics, X-rays harm the environment and living things around them, especially radiation workers. The impact that can result in cancer due to the accumulation of radiation dose exposure received by the body exceeds the specified threshold dose (Carrol, 1985). Therefore the use of Xrays as radio diagnostic in the health sector has been regulated by the government in Government Regulation No. 33 of 2007 concerning Safety of Ionizing Radiation and Security of Radioactive Sources and Decree of the Head of BAPETEN No. 01 / Ka-BAPETEN / V-99 concerning Provisions for Safety with Radiation.

Research on radiation output on X-ray devices has been carried out by Rahayu (2007), comparing the output characteristics of the Toshiba X-ray DRX-1824B model to the Toshiba DRX-1603B Model. The type of $\mathrm{X}$-ray devices used is conventional X-ray devices, the results of this study state that in general measurements of the radiation output characteristics of the two X-ray devices show that both planes are still suitable for use. Oktavina (2009), examined the backscatter coefficient of diagnostic X-ray factors in the RQR (Radiation Qualities in Radio diagnostic) range of ISO Water Slab Phantom, that the backscattering factor in the $12.4 \times$ $12.4 \mathrm{~cm}$ radiation field increased with the quality of RQR radiation 5 to with RQR 10 . Research by Mukminah et al., (2010); Vallejo et al., (2019), who analyzed radiation output on Mobile X-ray devices, that the linearity of Mobile X-ray radiation output at Dr. Tadjudin Chalid Hospital is still within the limits of allowable tolerance $(10 \%)$. Other studies have also mentioned the quality of X-ray output showing that leakage of X-ray aircraft units can affect the quality of X-ray output.

Based on the results of research that has been done before, then this research needs to be done on devices models contained in Kasih Ibu Kedonganan Hospital specializes in the quality of X-ray output on the influence of patient thickness.

\section{Materials and Methods}

The location of the study was at the Radiology Unit of Kasih Ibu Kedonganan Hospital. The study was conducted using the main equipment X-ray devices and radiation dosimeters and observed variables include $\mathrm{kV}, \mathrm{mA}$, exposure time, patient thickness and radiation output dose.

The research procedure starts with taking direct radiation output data when testing X-ray devices. For the accuracy of measurement results, data collection was carried out 5 times. With tube voltages ranging from 50 , $60,70,80$ and $90 \mathrm{kV}$, which are varied with different tube current values (mAs) in each measurement and concerning the thickness of the patient. From the variation in $\mathrm{kV}$, $\mathrm{mAs}$ and thickness of the patient $(\mathrm{cm})$ for the AP (Postero Anterior) and LAT (Lateral) examination. So that the amount of radiation output can be determined in $\mathrm{mGy}$ or $\mathrm{mA}^{-1}$.

The research data is quantitative data that is analyzed in a comparative descriptive and statistical way, by looking at and comparing the observations of the research conducted. Data on the average results of the calculation of exposure and patient thickness were statistically analyzed using ANOVA (Analysis of Variance). ANOVA test results were significantly different $(\mathrm{P} \leq 0.05)$ followed by LSD test so that differences can be seen between treatments (Winata, 2009). 


\section{Results and Discussions}

The X-ray planes used in this study are conventional X-ray planes for general radiographic examinations. The direct output of radiation output data is taken when testing X-ray devices. For the accuracy of measurement results, data collection was carried out 5 times. With tube voltages (kV) ranging from 50, 60, 70, 80 and $90 \mathrm{kV}$, which are varied with different tube current values (mAs) in each measurement and concerning patient thickness. Dose measurements are carried out on two examination projections namely PA and LAT projections. The measurement results can be shown in Figure 1. Graph A shows an examination with a patient's body thickness of $22 \mathrm{~cm}$, graph B for a patient's body thickness of $24 \mathrm{~cm}$, graph C with a patient's body thickness of $27 \mathrm{~cm}$ and graph D of a patient's body thickness of $30 \mathrm{~cm}$ (Istiyanto, 2015).

Figure 1 shows that the lowest radiation dose for PA and LAT projections occurs at the tube current regulation of 1, $60 \mathrm{mAs}$ and the highest radiation dose occurs at the tube current regulation $25 \mathrm{mAs}$. The relationship between radiation dose and X-ray tube current shows a linear relationship because the greater the tube current used, the higher the level of film density and the resulting radiation dose (Akhadi, 2000; Sutapa et al., 2018). Bigitu also occurs in X-ray voltage, the greater the voltage used, the greater the X-ray penetrability is also deeper and the radiation dose is greater.
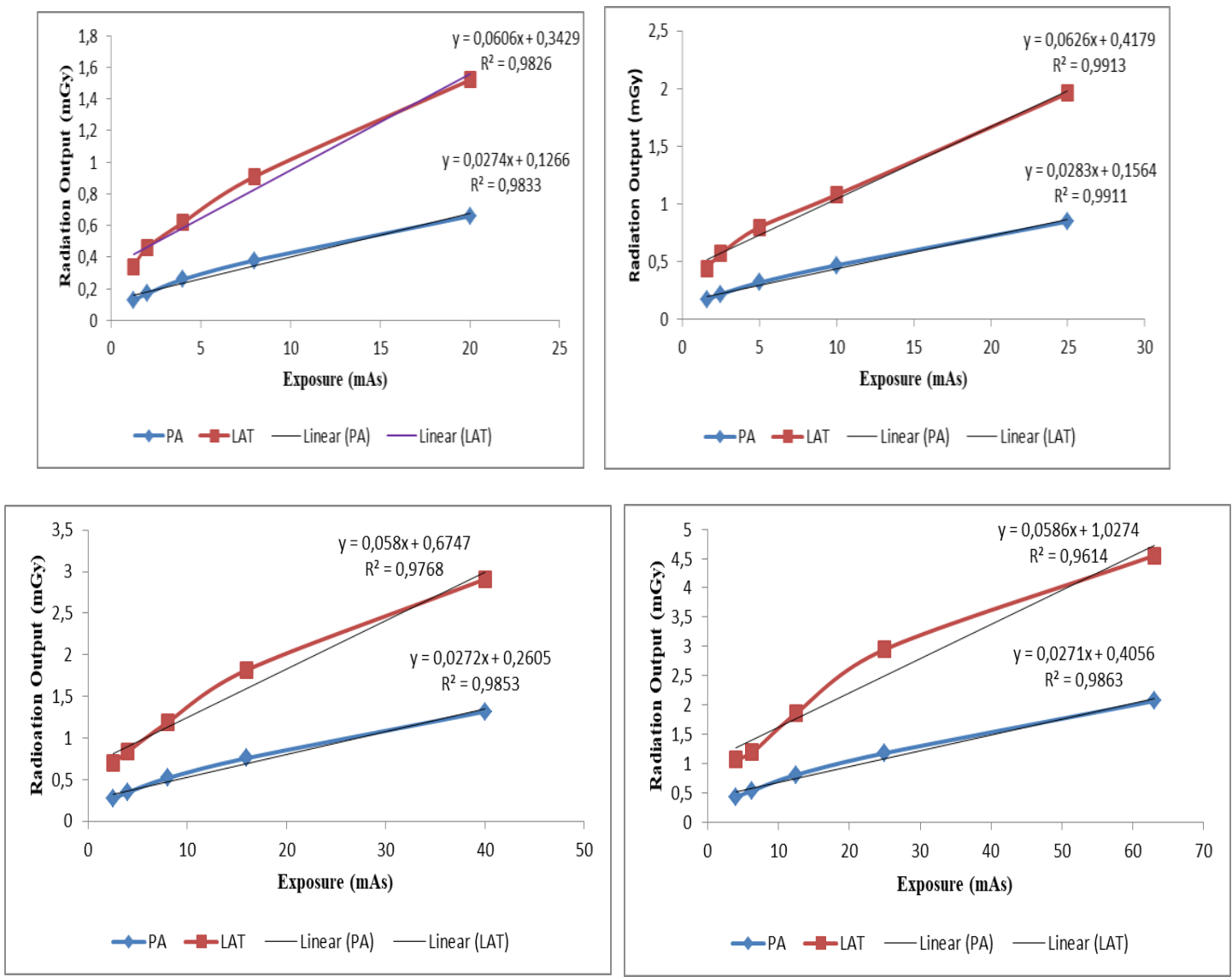

Figure 1. Radiation Dosage Graph for Each Exposure with Thicken Body Thickness

Graph 1A shows that the linearity coefficient in the PA projection is 0.028 and the LAT is 0.063 . Graph 1B with linearity coefficient on PA projections is 0.027 and LAT is 0.057 . Graph $1 \mathrm{C}$ with the linearity coefficient on the PA projection is 0.027 and LAT is 0.058 . Graph $1 \mathrm{D}$ with the linearity coefficient on the PA projection of 0.027 and LAT of 0.059 . The linearity coefficient for all graphs is still below $10 \%$ so that X-ray planes can still function properly. The relationship of radiation output dose to tube current is the absorbing dose received by

Ratnawati, I. G. A. A., Suandayani, N. K. T., \& Sutapa, G. N. (2019). The linearity of $x$-ray devices radiation output and its relationship with patient thickness. International Journal of Physical Sciences and Engineering, 3(3), 1-6. https://doi.org/10.29332/ijpse.v3n3.351 
the patient will be even greater if the voltage and current regulation are increased and also affects the amount of intensity and penetrating X-rays produced. The amount of X-ray intensity that is given greatly affects the quality of the resulting imaging (Sianturi et al., 2018).

The relationship between the thickness of the patient's body with the amount of dose received by the patient gives a more rational picture compared to measurements of body weight. The graph of the relationship between the patient's body thickness and radiation dose can be shown in Figure 2 .

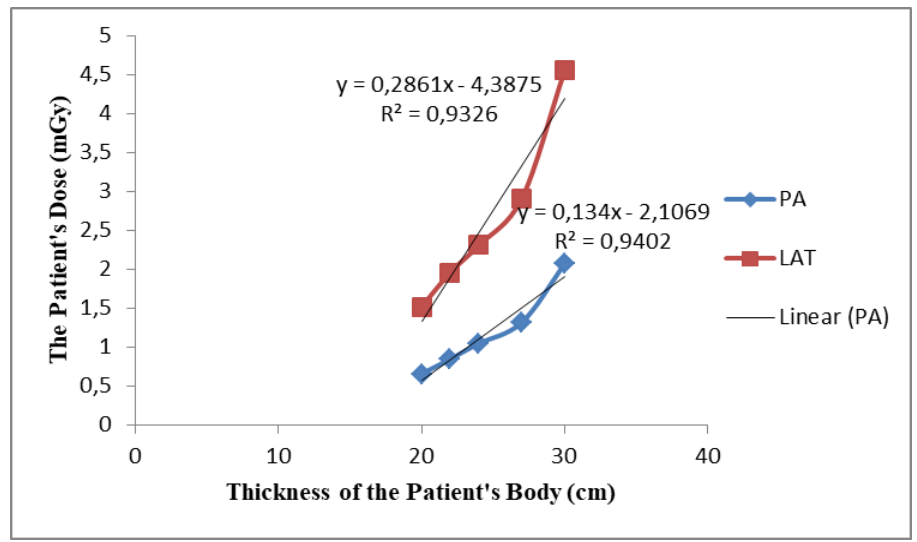

Figure 2. Radiation Dosage Graph of Patient Body Thickness

Figure 2 shows that the change in the thickness of the patient's body is thin, then the increase in radiation dose received by the patient is not so large. But on changes in the thickness of the patient's thick body, an increase in radiation dose received by the patient is very large. So that it can be stated by increasing the patient's body thickness significantly $(\mathrm{P} \leq 0.05)$ can increase the patient's dose reception.

\section{Conclusion}

All radiation output measurements (mGy) concerning several values of exposure (mAs) show linear linearity of radiation output. X-ray radiation output linearity of Kasih Ibu Kedonganan Hospital with tolerance below $10 \%$. The patient's body thickness significantly $(\mathrm{P} \leq 0.05)$ received a larger dose.

\section{Acknowledgments}

Acknowledgments to Udayana University for funding the implementation of this research through the Unud BLU DIPA in the fiscal year 2019 following the Letter of Appointment for the Study Program Leading Research (SPLR). 


\section{References}

Akhadi, M. (2000). Fundamentals of Radiation Protection, First Printing, Jakarta, PT. Rineka Cipta.

Carrol Q. B. (1985). Principle of Radiographic Exposure Processing and Quality Control, Third Edition, USA, Charles C, Thomas Publisher.

Chamber, H. (1983). Introduction to Health Physics, (translated by Achmad Toekiman), Semarang, IKIP Press.

Istiyanto, J. E., (2015). Regulation of the Head of the Nuclear Power Supervisory Agency Number 15 of 2015 Concerning Radiation Safety in Production of Diagnostic and Interventional Radiological X-rays. BAPETEN Jakarta.

Mukminah, N. R., Iswandi, \& Ihsan. (2010). Linearity Analysis of Radiation Outputs on Mobile X-Ray Using Piranha, Journal of Science and Technology, UIN Hasanudin Makasar.

Oktavina, R. (2009). Strategic Management Model for Micro and Small Snack Food Business Performance Evaluation. Business Economics Scientific Journal, 14(2).

Rahayu, A. (2007). Comparison of Output Characteristics Between the Toshiba X-ray Model DRX-1824B and the Toshiba Model DRX-1603B. Journal of Science and Technology, UIN Hasanudin Makasar.

Sianturi, H. A., Rianna, M., Sembiring, T., \& Situmorang, M. (2018). Measurement and Analysis of Output Radiation Dose on X-Ray Device over 10 Years at Hospitals in Medan City. Journal of Aceh Physics Society, 7(1), 1-5.

Sutapa, G. N., Yuliara, I. M., \& Ratini, N. N. (2018). Verification of dosage and radiation delivery time breast cancer (Mammae $\mathrm{Ca}$ ) with ISIS TPS. International Journal of Health Sciences, 2(2), 78-88. https://doi.org/10.29332/ijhs.v2n2.174

Vallejo, R. S. R., Gámez, M. R., Espinales, A. M. S., \& Pérez, A. V. (2019). Effects of thermal radiation using wood stoves on population health. International Research Journal of Management, IT and Social Sciences, 6(5), 18. https://doi.org/10.21744/irjmis.v6n5.656

Winata, D. O. (2009). Diagnostic X-Ray Factor Backscatter Coefficient in the ROR Range (Radiation Qualities in Radiodiagnostic).

Ratnawati, I. G. A. A., Suandayani, N. K. T., \& Sutapa, G. N. (2019). The linearity of x-ray devices radiation output and its relationship with patient thickness. International Journal of Physical Sciences and Engineering, 3(3), 1-6. https://doi.org/10.29332/ijpse.v3n3.351 


\section{Biography of Authors}

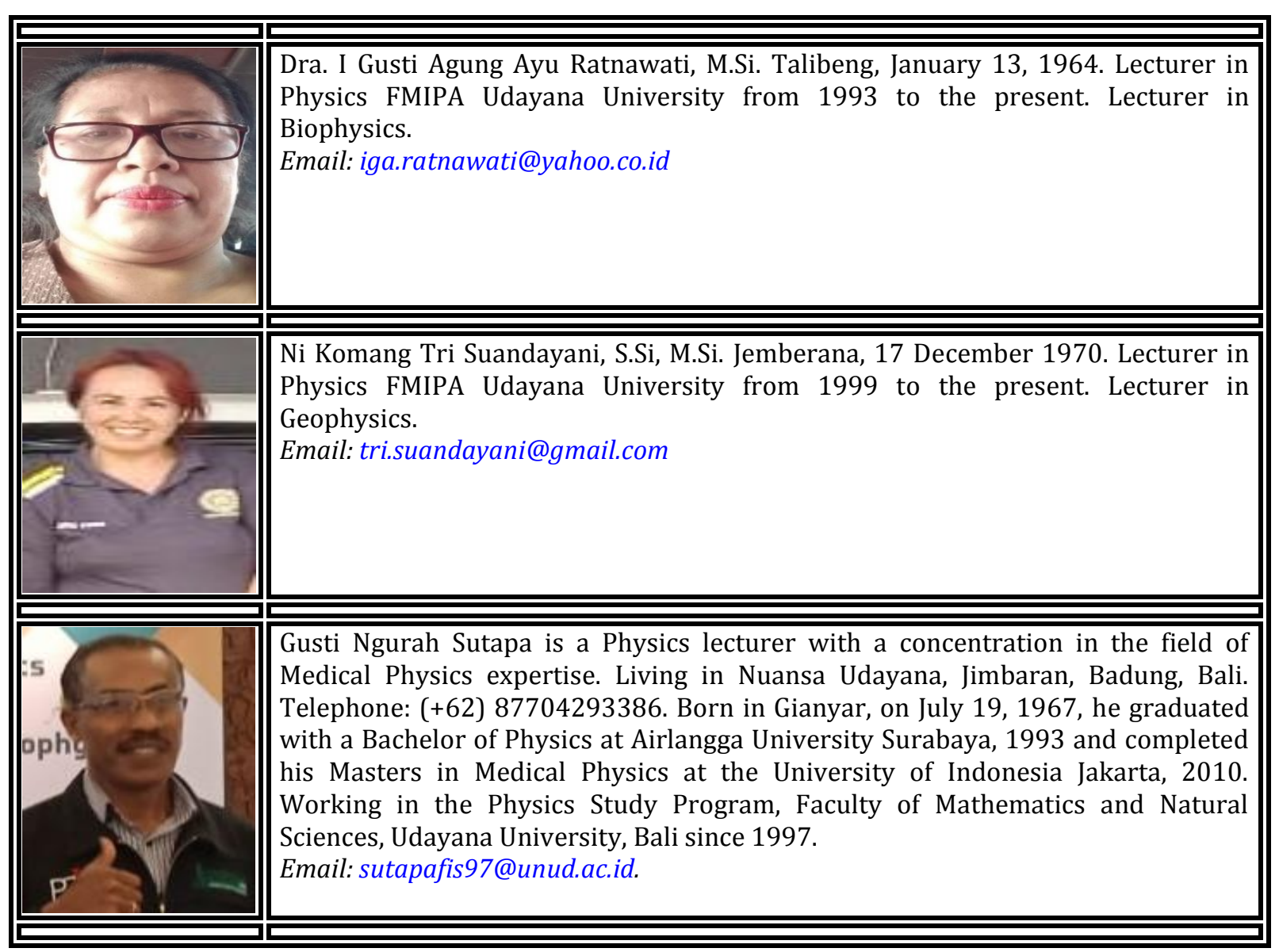

